\title{
Stress Corrosion Cracking of Pipeline Steel
}

\author{
Eihachiro Sunami, Masayuki Tanimura \\ and Gennosuke Tenmyo \\ Technical Research Center, Nippon Kokan K.K.*
}

\begin{abstract}
Research has been conducted to learn whether hydrogen sulfide stress corrosion cracking and hydrogen-stress cracking occur to pipeline steels of higher strength levels. Materials tested are low carbon and low alloy steels heat treated to give yield strengths in the region of 30 to $100 \mathrm{~kg} / \mathrm{mm}^{2}$. Delayed-failure tests, measurements of the degree of embrittlement and those of the hydrogen permeation rates through steel plate in contact with a $\mathrm{H}_{2} \mathrm{~S}$ solution and under conditions simulating cathodic protection were carried out. The damages in the $\mathrm{H}_{2} \mathrm{~S}$ solution or under cathodic charging were delayed failure and the blistering. Hydrogen was the direct cause of these damages. The relationship between the cathodic current density and the surface hydrogen concentration $C_{s}$ was as follows: $\log C_{s}(\mathrm{cc} / 100 \mathrm{~g} \mathrm{Fe})=3.84 \log i\left(\mathrm{~mA} / \mathrm{cm}^{2}\right)+0.16$. The sensitivity to delayed failure and blistering in the $\mathrm{H}_{2} \mathrm{~S}$ solution and under the cathodic charging did not increase or a little decreased with increase of yield strength up to $60 \mathrm{~kg} / \mathrm{mm}^{2}$.
\end{abstract}

\section{Introduction}

Transport of natural gas in pipelines is undergoing a rapid growth in this country. To transmit the maximum quantity of gas, pipelines have been constructed of higher-strength steels.

The use of high-strength steels for drill pipe in sour oil and gas fields in foreign countries ${ }^{1)}$ and the use of steels with tensile strength of $80 \mathrm{~kg} / \mathrm{mm}^{2}$ for LPG storage tanks in this country ${ }^{2 \prime}$ brought about a problem caused by hydrogen-sulfide stress corrosion cracking.

To prevent external corrosion of buried pipelines in contact with various soils and in the presence of stray current, cathodic protection and protective coatings are applied to pipelines. In spite of these precautions, stress corrosion cracking and hydrogen-stress cracking, due to the hydrogen evolution at defects in coatings under cathodic protection have been found. ${ }^{31}$

Hydrogen in steel has several detrimental effects: For example, it may cause a loss in ductility or internal blistering in low or medium strength steels. When it enters into high strength steels, hydrogen-stress cracking may occur under a tensile stress.

The primary objective of this research is to determine whether hydrogen sulfide stress corrosion cracking and hydrogen-stress cracking occur to pipelines using higher strength steels and to find correlations between the strength level, applied stress and hydrogen concentration.

\section{Experimental}

Chemical compositions and mechanical properties of materials used in this study are listed in Tables 1 and 2, respectively. Specimens in the form of plate and pipe were in the as-rolled condition or heat treated to give yield strengths in the region of 30 to $100 \mathrm{~kg} / \mathrm{mm}^{2}$. They were taken parallel to the rolling direction. Specimens of Steel 2, 3, 7 were cut from various positions of welded pipes having large diameters.

2.1. Hydrogen Sulfide Stress Corrosion Cracking Delayed failure tests were carried out by the constant-loaded tensile apparatus in a $0.5 \%$ acetic acid solution saturated with $\mathrm{H}_{2} \mathrm{~S}(\mathrm{pH}=3.1$, $3000 \mathrm{ppm} \mathrm{H}_{2} \mathrm{~S}$ ). Time to failure was recorded on a timer. For the measurement of the decrease in ductility, the tensile test specimen was immersed in the $\mathrm{H}_{2} \mathrm{~S}$ solution for $500 \mathrm{hrs}$ without stress and then tensile-tested in air. The degree of embrittlement was calculated from the decrease in elongation or reduction of area. The surface concentration of hydrogen which was formed by corrosion reactions with the $\mathrm{H}_{2} \mathrm{~S}$ solution and diffused into steel was measured by the hydrogen permeation method.

\subsection{Hydrogen-stress Cracking}

Delayed failure tests under cathodic current were also carried out by the constant-loaded tensile apparatus. The electrolyte was a $4 \% \mathrm{H}_{2} \mathrm{SO}_{4}$ solution to which $0.1 \mathrm{~g}$ As per liter of the electrolyte was added. The current densities at the exposed surface of the specimen were in the range of 0.1 
Table 1. Chemical compositions ( $\%)$.

\begin{tabular}{ccccccccccc}
\hline Steel & $\mathrm{C}$ & $\mathrm{Si}$ & $\mathrm{Mn}$ & $\mathrm{P}$ & $\mathrm{S}$ & $\mathrm{Cu}$ & $\mathrm{Cr}$ & $\mathrm{Ni}$ & $\mathrm{Mo}$ & \\
\hline 1 & 0.20 & 0.20 & 1.11 & .022 & .020 & & & & & \\
2 & 0.14 & 0.34 & 1.02 & .021 & .017 & 0.17 & 0.30 & & & \\
3 & 0.18 & 0.39 & 1.45 & .024 & .011 & 0.03 & 0.03 & & & $\mathrm{Nb} 0.02$ \\
4 & 0.15 & 0.25 & 0.78 & .010 & .010 & 0.26 & 0.56 & 0.88 & 0.42 & $\mathrm{~V} 0.04$ \\
5 & 0.42 & 0.31 & 0.83 & .010 & .003 & 0.04 & 0.95 & 1.59 & 0.20 & \\
6 & $0.15 / 0.17$ & $0.22 / 0.90$ & $1.20 / 1.30$ & $.015 / .020$ & $.010 / .015$ & $<0.48$ & $<0.47$ & $<0.50$ & & $\mathrm{Nb} \mathrm{VTiZr}$ \\
7 B. & 0.12 & 0.24 & 1.32 & .018 & .008 & 0.16 & 0.15 & & 0.22 & $\mathrm{~V} 0.04$ \\
D. & 0.10 & 0.15 & 2.00 & & & & 0.50 & & 0.50 & \\
\hline
\end{tabular}

Table 2. Mechanical properties.

\begin{tabular}{|c|c|c|c|c|c|c|}
\hline Steel & $\begin{array}{c}\text { Heat- } \\
\text { treatment }\end{array}$ & $\begin{array}{l}\text { A.P.I. } \\
\text { grade }\end{array}$ & $\underset{\mathrm{kg} / \mathrm{mm}^{2}}{\text { Y.S. }}$ & $\underset{\mathrm{kg} / \mathrm{mm}^{2}}{\text { T.S. }}$ & $\begin{array}{l}\mathrm{El} \\
\%\end{array}$ & $\begin{array}{r}\text { R.A } \\
\%\end{array}$ \\
\hline 1 & As-roll. & $X-52$ & 42.7 & 55.7 & 20.0 & 54 \\
\hline 2 & As-roll. & $X-52$ & 37.3 & 51.6 & 20.4 & 62 \\
\hline 3 & As-roll. & $X-65$ & 51.8 & 65.4 & 30.0 & 67 \\
\hline \multirow[t]{2}{*}{4} & Q.T. & $X-80$ & 59.9 & 70.3 & - & - \\
\hline & . & $X-100$ & 73.1 & 79.1 & - & - \\
\hline \multirow[t]{2}{*}{5} & Q.T. & $X-120$ & 84.4 & 95.0 & 17.6 & 63 \\
\hline & & $\mathrm{X}-145$ & 101.3 & 120.0 & 11.4 & 59 \\
\hline 6 & $\begin{array}{l}\text { As-roll. } \\
\text { N. Q.T. }\end{array}$ & $X-52-X-70$ & $33 / 53$ & $50 / 61$ & $25 / 37$ & $70 / 68$ \\
\hline \multirow[t]{2}{*}{7} & Q.T. & $\mathrm{X}-80 \quad$ B. & 63.6 & 67.7 & 18.8 & 68 \\
\hline & & D. & 62.0 & 67.4 & 13.0 & 67 \\
\hline
\end{tabular}

to $100 \mathrm{~mA} / \mathrm{cm}^{2}$. The relationship between the cathodic current density and the surface concentration of hydrogen was also determined by the hydrogen permeation method.

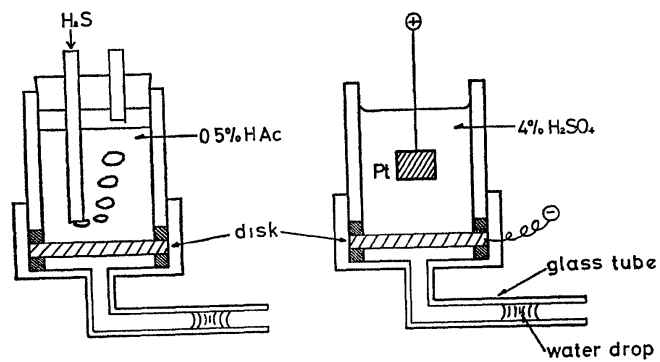

Fig. 1. Hydrogen permeation devices.

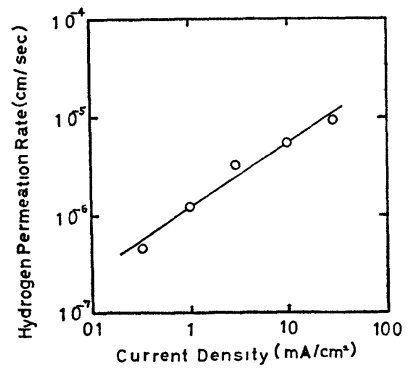

Fig. 2. Effect of current density on hydrogen permeation rate.
Figure 1 shows the general view of the measuring devices. Some of the gas generated by the cathodic reaction or the corrosion reaction with the $\mathrm{H}_{2} \mathrm{~S}$ solution at the surface diffused into the plate to the opposite side and moved a waterdrop in the calibulated glass tube. The gas-chromatographic analysis showed that the permeated gas was hydrogen. The waterdrop began to move after a definite time at a constant rate depending on the thickness of the plate. Figure 2 shows that the logarithm of the hydrogen permeation rate $\left(\mathrm{cm}^{3} / \mathrm{cm}^{2} \cdot \mathrm{sec}\right)$ changes linearly with the logarithm of current density $\left(\mathrm{mA} / \mathrm{cm}^{2}\right)$. The permeation rate under corrosion by the $\mathrm{H}_{2} \mathrm{~S}$ solution was equivalent to that under cathodic charging at a current density of $5 \mathrm{~mA} / \mathrm{cm}^{2}$. From time-lags and permeation rates surface concentrations and the diffusion coefficient of hydrogen in the steel plate were obtained. The total amount of hydrogen permeated per unit area $\left(Z \mathrm{~cm}^{3} / \mathrm{cm}^{2}\right)$ was obtained by solving the Fick's second law. In Fick's second law

$$
\frac{\partial C}{\partial t}=\frac{\partial}{\partial x}\left(D \frac{\partial C}{\partial t}\right)
$$

let the cathodic side of the plate be $x=0$ and the waterdrop side be $x=l$, where $l$ is the thickness of 
the plate. The boundary conditions are given by

$$
\begin{aligned}
& C=0 \text { for } 0 \leqq x \leqq l, \text { at } t \leqq 0 \\
& C=C_{s} \text { for } x=0, \text { at } t>0 \\
& C=0 \text { for } x=l, \\
& Z=\frac{D \cdot C_{s}}{l}\left[t-\frac{l^{2}}{6 D}\right]
\end{aligned}
$$

where $\quad D=$ diffusion coefficient $\left(\mathrm{cm}^{2} / \mathrm{sec}\right)$

$\mathrm{C}_{s}=$ surface concentration of hydrogen

$$
Z=P(t-L)
$$

where $\quad P=\frac{D \cdot C_{s}}{l}$ :

permeation rate $\left(\mathrm{cm}^{3} / \mathrm{cm}^{2} \cdot \mathrm{sec}\right)$

$$
L=\frac{l^{2}}{6 D}: \text { time-lag }
$$

and

$$
C_{s}=\frac{P \cdot l}{D}
$$

The surface concentration of hydrogen under cathodic charging and corrosion by the $\mathrm{H}_{2} \mathrm{~S}$ solution are shown in Table 3. Within the limit of this experiment the increase of current density means the increase of surface concentration of hydrogen.

Table 3. Saturated hydrogen concentrations.

\begin{tabular}{lllllll}
\hline \hline $\mathrm{mA} / \mathrm{cm}^{2}$ & 0.33 & 1 & 3 & 10 & 3.3 & $\mathrm{H}_{2} \mathrm{~S}^{*}$ \\
\hline $\mathrm{cc} / 100 \mathrm{~g} \mathrm{Fe}$ & 0.28 & 0.79 & 1.8 & 3.2 & 7.3 & 2.5 \\
\hline$D=2.26 \times 10^{-6} \mathrm{~cm}^{2} / \mathrm{sec}$. \\
* Surface concentration of hydrogen under corrosion \\
in the $\mathrm{H}_{2} \mathrm{~S}$ solution.
\end{tabular}

\section{Results and Discussion}

3.1. Hydrogen Sulfide Stress Corrosion Cracking

Figure 3 shows the relationships between applied stress and time to failure for steels 3, 4, 5 in the $\mathrm{H}_{2} \mathrm{~S}$ solution. There is a lower critical stress under which no failure occurs. The maximum time of loading was $200 \mathrm{hrs}$. The relationships between the strength level and the lower critical stress for all steels tested are shown in Figure 4. The lower critical stresses were about $75 \%$ of the yield strength for steels having a yield strength up to $60 \mathrm{~kg} / \mathrm{mm}^{2}$. They decreased with the increase of the yield strength above $70 \mathrm{~kg} / \mathrm{mm}^{2}$. Therefore, below a yield strength of $60 \mathrm{~kg} / \mathrm{mm}^{2}$ higher strength steels fractured at a longer time for all heat treatments. (Figure 5)

The times to failure of the transverse specimens were shorter than those of longitudinal ones and the lower critical stresses of the former were a ${ }_{1}$ ittle lower than those of the latter specimens. For this strength range, the lower critical stresses of the type c specimens i.e. longitudinal in the weld metal and the type $\mathrm{d}$ specimens i.e. transverse to the weld line were almost equal to those of the type a specimens i.e. longitudinal to the pipe in the base metal, and the type $\mathrm{b}$ specimens i.e. circumferential to the pipe in the base metal (Figure 6).

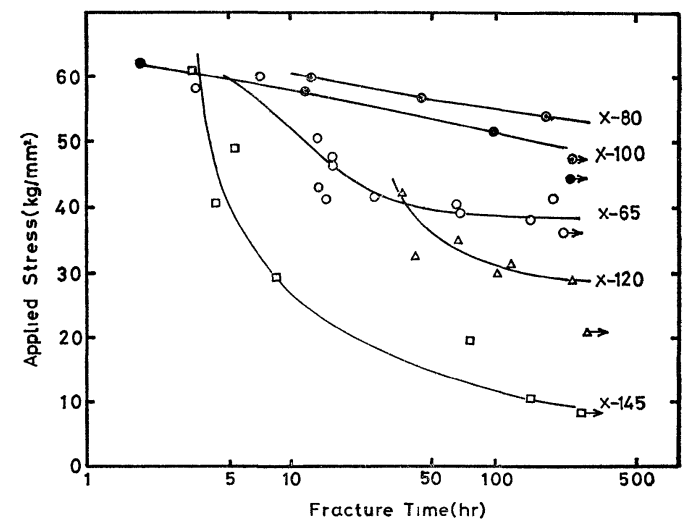

Fig. 3. Delayed failure curves in the $\mathrm{H}_{2} \mathrm{~S}$ solution.

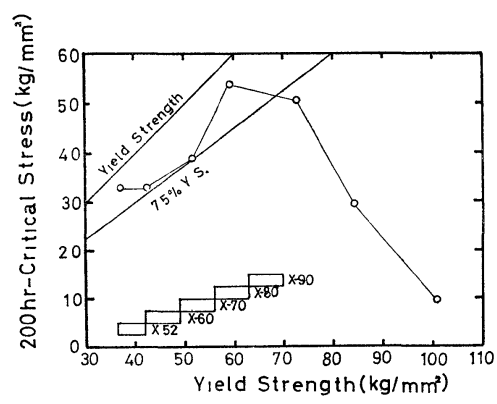

Fig. 4. Effects of yield strength on $200 \mathrm{hr}$-critical stress in the $\mathrm{H}_{2} \mathrm{~S}$ solution.

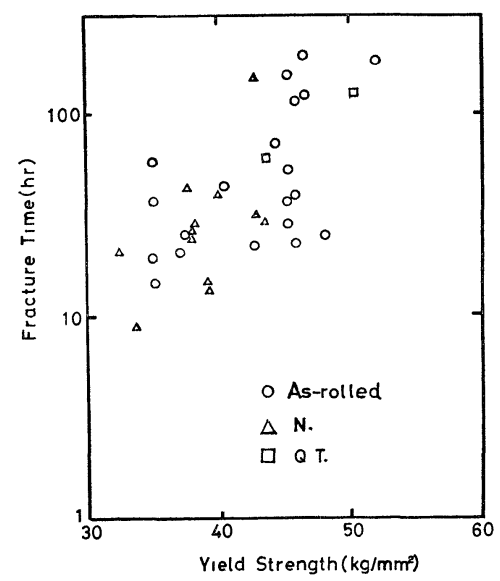

Fig. 5. Effect of yield strength on fracture time (Steel 6, applied stress $=30 \mathrm{~kg} / \mathrm{mm}^{2}$ ). 
The cracks in steels quenched and tempered to higher strength levels appeared along the prioraustenite grain boundaries. In the as-rolled steels cracks were observed to connect inner blisters elongated in the rolling direction (Figure 7). The blisters were formed along the inner interfaces between the matrix and sulfide-inclusions elongated by the rolling. Specimens from plates and pipes were immersed in the $\mathrm{H}_{2} \mathrm{~S}$ solution for $500 \mathrm{hrs}$ without stress, and then cut for cross sectional examination. There were many blisters around which strains of microstructure were observed. The blisters were formed by the pressure of hydrogen entering from the steel surface and the pressure of hydrogen seems to be high enough to induce the plastic deformations in lower strength steels. As the blisters played an important role in the delayed failure tests, decrease in elongation and reduction of area, which were thought more sensitive to the blistering, were measured. A failure of pipeline by burst of a blister was reported. In the yield strength range of 30 to $50 \mathrm{~kg} / \mathrm{mm}^{2}$, the higher the strength, the lower the degree of embrittlement in

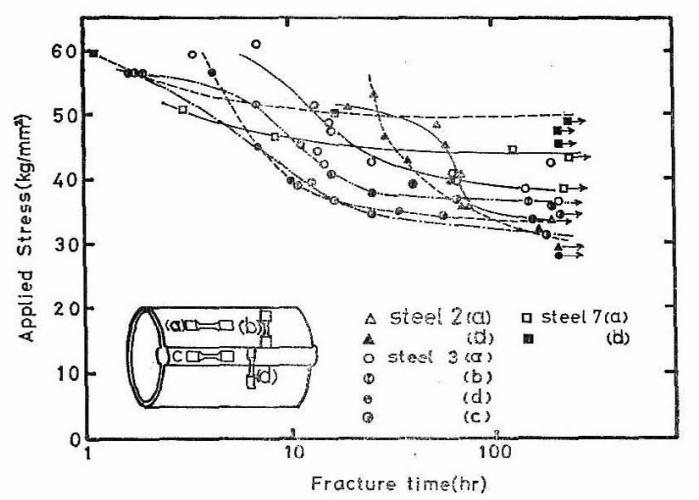

Fig. 6. Effect of specimen position and welding on delayed failure curves.

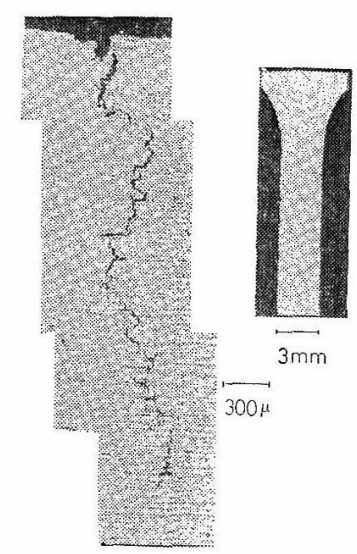

Fig. 7. Cracks and blisters. terms of the reduction of area

$$
\begin{gathered}
\left(=\frac{\text { R.A. before immersion-R.A. after immersion }}{\text { R.A. before immersion }}\right. \\
\quad \times 100) \text { (Figure } 8) .
\end{gathered}
$$

Figures 8 and 9 show that heat treatments do not affect the sensitivity. Figure 9 shows that the increase in ductility of low strength steel increases the degree embrittlement. The concentration of the absorbed hydrogen in steel 6 was analized by vacuum extraction method. Specimens $(\phi=6 \mathrm{~mm}$, $l=30 \mathrm{~mm}$ ) were immersed for $500 \mathrm{hrs}$ in the $\mathrm{H}_{2} \mathrm{~S}$

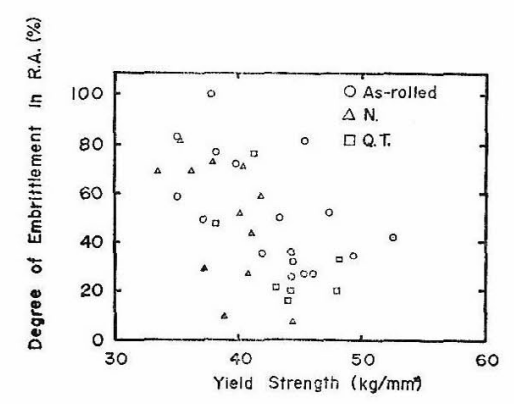

Fig. 8. Effect of yield strength on degree of embrittlement (Steel 6).

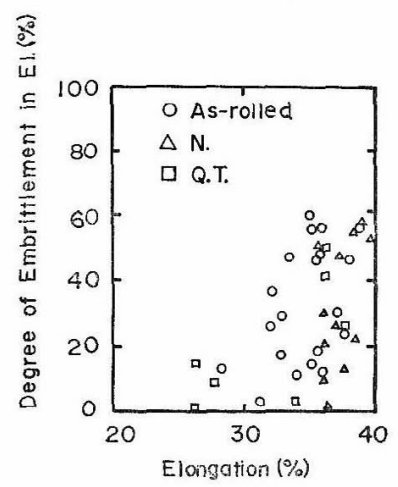

Fig. 9. Effect of elongation on degree of embrittlement (Steel 6).

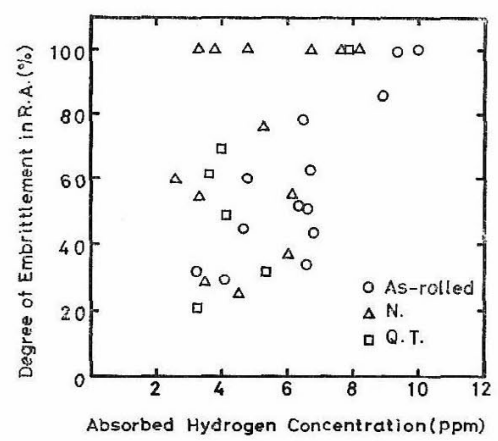

Fig. 10. Effect of hydrogen concentration on degree of embrittlement in R.A. (Steel 6). 
solution. Although the degree of embrittlement scattered for the same concentration of hydrogen, it had a tendency to increase with increase of the concentration of hydrogen (Figure 10).

\subsection{Hydrogen-stress Cracking}

Under cathodic currents the ratio of the critical stress to the yield strength decreased as the yield strength increased above $60 \mathrm{~kg} / \mathrm{mm}^{2}$ (Figure 11). As the current density increased, the critical stress of higher strength steels decreased rapidly.

At a lower cathodic current density $\left(0.1 \mathrm{~mA} / \mathrm{cm}^{2}\right)$ the critical stress of a high strength steel $(\mathrm{X}-145)$ was lower than that at $0.3 \mathrm{~mA} / \mathrm{cm}^{2}$. At this current density deep pitting corrosion occurred on the surface of the specimen and it fractured at a pit. The range of the current density allowable for the high strength steel is apparently narrow. These results combined with those of the measurement of the hydrogen permeation rates clearly indicate that the critical stress of high strength steels was reduced by the small increase of the surface concentration of hydrogen and that of low strength steels was not influenced.

From the ratio of the critical stress to the yield strength at the current density of $5 \mathrm{~mA} / \mathrm{cm}^{2}$ in Figure 11, the critical stresses for the steels in the $\mathrm{H}_{2} \mathrm{~S}$ solution can be estimated. However all of values thus obtained were higher than the critical stresses obtained directly in the $\mathrm{H}_{2} \mathrm{~S}$ solution. The difference would come from the corrosion reaction with $\mathrm{H}_{2} \mathrm{~S}$ on the surface.

Below an yield strength corresponding to $\mathrm{X}-80$, the critical stresses are more than $75 \%$ of yield strength at cathodic current densities up to $100 \mathrm{~mA} /$ $\mathrm{cm}^{2}$. To relate this result to the susceptibility to hydrogen-stress cracking induced by cathodic protection of high strength steel pipelines, it is necessary to ascertain the local current density at the surface of cathodically protected pipelines. Unfortunately, the current density at holiday areas is not known definitely. Using an estimated value

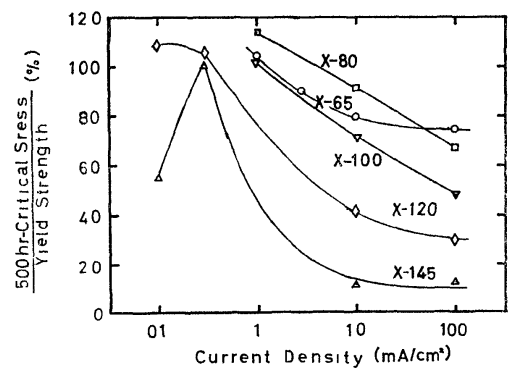

Fig. 11. Effect of current density on $500 \mathrm{hr}$ critical stress. of $1 \mathrm{~mA} / \mathrm{cm}^{2,4)}$ it can be seen that pipeline steels (up to $X-80$ ) are not susceptible to hydrogenstress cracking.

\section{Conclusion}

1. Delayed failure tests, measurements of the hydrogen permeation rates, measurements of the degree of embrittlement were carried out in the $0.5 \%$-acetic acid saturated with $\mathrm{H}_{2} \mathrm{~S}$ gas or under the condition of cathodic protection.

2. The damages in the $\mathrm{H}_{2} \mathrm{~S}$ solution or during the cathodic charging were delayed failure and blistering. Hydrogen was the direct cause of these damages. Furthermore blistering played an important role in the delayed failure of lower strength steels.

3. The relationship between the cathodic current density and the surface hydrogen concentration was as follows:

$\log C_{s}(\mathrm{cc} / 100 \mathrm{~g} \mathrm{Fe})=3.84 \log i\left(\mathrm{~mA} / \mathrm{cm}^{2}\right)+0.16$

The surface hydrogen concentration of steel in the $0.5 \%$-acetic acid saturated with $\mathrm{H}_{2} \mathrm{~S}$ gas was about $2.5 \mathrm{cc} / 100 \mathrm{~g} \mathrm{Fe}$ and it was equivalent to cathodic charging at a current density of $5 \mathrm{~mA} / \mathrm{cm}^{2}$.

4. The blisters were formed by the pressure of hydrogen entering from the surface to the boundaries between the matrix and inclusions elongated by rolling.

5. The ability of steels to absorb hydrogen (including the reactivity on the surface) and the susceptibility to blistering may explain the occurrence of delayed failure by hydrogen.

6. The susceptibility to delayed failure and blistering in the $\mathrm{H}_{2} \mathrm{~S}$ solution and under the cathodic charging did not increase or a little decreased with increase of yield strength up to $60 \mathrm{~kg} / \mathrm{mm}^{2}$. The susceptibility increases with increase of yield strength above $70 \mathrm{~kg} / \mathrm{mm}^{2}$.

7. Pipelines using steels up to $\mathrm{X}-80$ are not susceptible to delayed failures by hydrogen sulfide stress corrosion and/or cathodic protection.

(Received September 28, 1973)

\section{Reference}

1) L. Cauchois, J. Didier \& E. Herzog: Corrosion, 13, 265 (1957).

2) J. I. W: Studies on the hydrogen sulfide stress corrosion cracking of high strength steel (1963).

3) A. G. A; Forth Symposium on line pipe research (1969).

4) L. J. McCowen \& A. R. Elsea: Corrosion, 21, 28 (1965). 